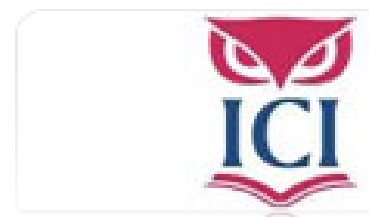

IUS. Revista del Instituto de Ciencias Jurídicas de Puebla A.C.

ISSN: 1870-2147

revista.ius@hotmail.com

Instituto de Ciencias Jurídicas de Puebla A. C.

México

Rogel Vide, Carlos

Origen y actualidad de los derechos de la personalidad

IUS. Revista del Instituto de Ciencias Jurídicas de Puebla A.C., núm. 20, 2007, pp. 260-282

Instituto de Ciencias Jurídicas de Puebla A. C.

Puebla, México 


\title{
ORIGEN Y ACTUALIDAD DE LOS DERECHOS DE LA PERSONALIDAD*
}

\author{
Carlos Rogel Vide*
}

SUMARIO

I. Bienes de LA PERSONALIDAd, INTRODUCCIÓN AL TEMA II. ELENCO Y CLASIFICACIÓN DE LOS BIENES DE LA PERSONALIDAD

III. DeRechos y deberes SObRe los bienes citados

IV. LOS DERECHOS DE LA PERSONALIDAD SOBRE LOS BIENES SOCIALES E INDIVIDUALES Y LOS Caracteres predicables de los mismos (el asunto en la Ley Orgánica 1/1982)

V. LOS DERECHOS DE LA PERSONALIDAD COMO CATEGORÍA Y LOS ANTECEDENTES DE LA MISMA

VI. Derechos humanos, derechos fundamentales y derechos de LA PeRsonalidad

VII. DifEREnCIas entre las CATEgorias antes Citadas

VIII. LA ACTUALIDAD DE LOS DERECHOS DE LA PERSONALIDAD Y SU COLISIÓN CON LAS LIBERTADES DE EXPRESIÓN E INFORMACIÓN

IX. HONOR, PERSONAS JURIDICAS Y PUBLICIDAD

X. Derechos de la PeRsonalidad y DERECHO MORAL DEL AUtOR

\section{RESUMEN}

El presente artículo aborda lo que la teoria del derecho civil ha denominado como derechos de la personalidad, los cuales se asientan sobre determinados bienes personales, derivados de bienes esenciales, entre los cuales se engloban la vida y la integridad corporal; en segundo término de bienes sociales e individuales, entre los cuales se incardinan el honor y la fama, la intimidad personal y familiar y la propia imagen; y de bienes corporales y psíquicos secun-

\section{ABSTRACT}

The present article approaches what the theory of the civil right has denominated as rights of the personality that settle on determined personal goods, derived of essential goods, inside which the life and the corporal integrity are included; in second term of social and individual goods, inside which the honor and the fame, the personal and family intimacy and the own image are; and of corporal property and psychic secondary as the

* El texto que sigue es el correspondiente a la conferencia pronunciada por su autor el día 7 de noviembre de 2001 en la Facultad de Derecho de la Universidad de La Coruña.

** Catedrático de derecho civil de la Universidad Complutense de Madrid y director de la Revista General de Legislación y Jurisprudencia. 
darios, como la salud física y psíquica, los sentimientos y la estima social. El autor plantea que existe una tendencia de que sobre todos los bienes citados se elevan derechos de la personalidad, entendidos como verdaderos derechos subjetivos extramatrimoniales, lo cual considera es una tendencia indiscriminada que no comparte y explica a lo largo del artículo. Aborda el empleo del término en la doctrina europea hasta su afianzamiento en la segunda mitad del siglo xIx. Establece la distinta ratio conceptual de los términos derechos humanos, derechos fundamentales y derechos de la personalidad, y culmina haciendo un estudio de la colisión entre algunos derechos de la personalidad como intimidad vs. libertad de expresión e información. physical and psychic health, the feelings and the social esteem. The author outlines that it exists a tendency that on all the mentioned goods rights of the personality rise, experts as true subjective rights, that which considers is an indiscriminate tendency that doesn't share and he explains along the article. It approaches the employment of the term in the European doctrine until their establishment in the second half of the XIX century. It establishes the differences of the terms human rights, fundamental rights and rights of the personality, and it culminates making a study of the collision among some rights of the personality like it intimidates vs. freedom of speech and information.

\section{BienES DE LA PERSONALIDAD, INTRODUCCIÓN AL TEMA}

En los pueblos civilizados y democráticos, donde la regla de la igualdad reina, en compañía de la libertad y de la fraternidad, a todas las personas -y no sólo a las que integran la clase o la raza dominantes- se les reconocen bienes, atributos de la personalidad misma y trasunto de ésta por la propia naturaleza de las cosas - para muchos- por voluntad del Sumo Hacedor de todas ellas. Hablo de la vida, de la intimidad, del honor y de la fama, entre otros bienes.

En los pueblos primitivos o en aquellos que, no siéndolo, no respetan la libertad ni la igualdad de todos los hombres; en los pueblos que no predican ni practican la fraternidad, el reconocimiento de los bienes citados es parcial o no existe respecto de determinadas gentes de determinadas razas o condiciones (esclavos, siervos, judíos, etc.).

En Roma, por ejemplo, los esclavos carecían, en principio y a reserva de ciertos peculios ${ }^{1}$, de bienes y derechos, siendo considerados, incluso

${ }^{1}$ A decir de Ortega y Carrillo de Albornoz, Derecho privado romano, Málaga, 1999, p. 31, el derecho 
y salvando las distancias existentes entre ellos y las cosas inertes, como cosas susceptibles de tráfico jurídico desde su misma gestación, lo cual posibilitaba compraventas de cosa futura cuyo objeto era el partus ancillae -el parto de la esclava- y en poco se distinguían de las relativas a los partos de los animales irracionales en todo momento.

Podría pensarse que eso -aberrante para nosotros- es propio de épocas muy pasadas. Craso error. No sólo conviene recordar que en España - como en los Estados Unidos de Lo que el viento se llevó- la esclavitud fue abolida en la segunda mitad del siglo xIx - mitad en la que, curiosamente o no tanto, alumbra, cual hemos de ver, la categoría de los derechos de la personalidad-, sino que también conviene recordar que en África, hoy, existen esclavos, miles y miles de esclavos que se compran y se venden por unos cuantos dólares. Conviene recordar, asimismo, que en 1940 y en libros de civilistas europeos de renombre que no quiero traer a colación, podría leerse que determinadas consideraciones y derechos estaban reservados a los individuos de la raza superior, no correspondiendo a otros, miembros de las que no lo eran, sobre todo a los de aquellas que se quería exterminar. Conviene recordar, en fin, que en los tiempos que corren, fanatismos, extremismos, nacionalismos exacerbados y otros muchos ismos desprecian la vida y la integridad física, privando de la una y de la otra, sin piedad, a personas inocentes.

\section{Elenco Y CLASIFICACIÓN DE LOS BIENES DE LA PERSONALIDAD}

Sabido es que el reconocimiento de los bienes de la personalidad no es, desgraciadamente, una constante espacial ni temporal en los ordenamientos jurídicos y sabido, también, que el nuestro es modélico en el sentido de tal reconocimiento, cabe afrontar ya, con un mínimo detenimiento, el elenco de dichos bienes y la incardinación de los mismos en categorías diversas.

- $\mathrm{Al}$ respecto y en primer lugar, se habla de bienes esenciales, dentro de los cuales se engloban la vida y la integridad corporal, citados aquí por todos los autores, y las libertades civiles, que algunos traen a colación en esta sede y sobre las que volveremos más tarde. Dentro de las libertades dichas, el maestro Carbonnier ${ }^{2}$ cita las libertades físicas -de locomoción,

romano admitió que el esclavo, al igual que el filius, pudiese administrar un pequeño patrimonio ( $p$ culium) con autorización de su dueño.

${ }^{2}$ Carbonnier, Droit civil, 1, París, 1971, p. 252. 
de hacer o no hacer, de quedarse en casa-, morales - de modo de vida, de conciencia- y profesionales -de comercio e industria, de trabajo-. Tales libertades, como puede verse, no se confunden con las libertades públicas -de expresión, reunión o información- que los ciudadanos tienen constitucionalmente reconocidas frente a los poderes del Estado, que no frente a otros ciudadanos o particulares.

- Se habla, en segundo término, de bienes sociales e individuales, dentro de los cuales se incardinan el honor y la fama, la intimidad personal y familiar y la propia imagen. Algunos hablan también, en esta sede, de la condición de autor y del nombre -y de los apellidos, de los seudónimos y de los títulos nobiliarios incluso.

Ha llegado a hablarse, incluso, de bienes corporales y psíquicos secundarios, como la salud física y psíquica, los sentimientos y la estima social, si bien quienes lo hacen reconocen la falta de independencia de los mismos, dado que se apoyan, a la postre, o están en relación directa con los bienes -esenciales, sociales o individuales que sean- reconocidos como principales, bienes que acabamos de referir.

\section{Derechos y deberes sobre los bienes citados}

Hay una cierta tendencia, una tendencia cierta a afirmar que, sobre todos los bienes citados, las personas tienen derechos de la personalidad, entendidos como verdaderos derechos subjetivos extrapatrimoniales. En mi opinión, tal tendencia indiscriminada es equivocada por lo que a continuación explicaré.

Respecto de los bienes esenciales, respecto de la vida y, con ciertas matizaciones, respecto de la integridad física, lo que existe es un deber general de respeto que vincula a todos, incluso al propio detentador de tales bienes, que no puede privarse de ellos a su voluntad, que no tiene un derecho sobre los mismos, que no tiene un poder de disposición sobre ellos.

En esta línea y hace mucho tiempo ya, un santo y gran maestro llamado Tomás de Aquino, discípulo y sucesor, en la cátedra de París, de Alberto de Colonia -San Alberto el Magno, andando el tiempo-, dijo, en civilista ortodoxo y clave de usufructo propio, que al hombre corresponde el usufructo sobre su propio cuerpo salva rerum substantia y correspondiendo la nuda propiedad a Dios, nuda propiedad que no es "nula", como cuenta Joaquín Rams que decía, equivocada e interesadamente, una señora aragonesa que él conoció. 
Siendo ello así, el suicidio es condenable, por mucho que no pueda castigarse al culpable, desalmado y devenido cosa mueble especial y cuasisagrada. Condenable es también la tentativa de suicidio, como condenable puede llegar a ser la automutilación.

Otra cosa es que las personas, en determinadas situaciones, puedan poner en peligro su vida, llevando a cabo actos de heroísmo, o que puedan comprometer prestaciones de servicios u obligaciones de hacer arriesgadas - piénsese en los bomberos o en los conductores de coches de carreras, por poner dos ejemplos-, pues lo que se persigue con tales actividades no es perder la vida, sino conservarla, conservando o salvando, de paso y en ocasiones, la vida de otros.

Respecto de la vida y de la integridad física, pues, y más que un derecho subjetivo propiamente dicho, lo que hay es un deber general de respeto que a todos constriñe, incluido el detentador mismo, el usufructuario de la vida y de la integridad física. En este sentido y refiriéndose a tales bienes, sentaba De Castro ${ }^{3}$, con toda su autoridad, "que la persona no tiene, en ellos, un auténtico derecho -ius dominativum-, que carece de un poder dispositivo sobre los mismos, que están fuera del comercio de los hombres (artículo 1.271 del Código Civil) y que sus facultades sobre aquéllos (impropiamente llamadas derechos), las de custos et administrator, se refieren fundamentalmente a la exigencia de protección y, en su caso, de indemnización".

En línea con lo anterior, pero matizándolo, se ha dicho:4 "El derecho a la vida comporta la obligación de respetar la vida ajena, que se impone a todos salvo, precisamente, a quien se defiende de una agresión injusta. Es, pues, un derecho-reflejo (el derecho llamado 'de legítima defensa') el que justifica el no-respeto de la obligación de no matar en ciertas circunstancias."

En línea con lo anterior también, pero en relación con la integridad física, cabe recordar, con Puig Brutau y Puig Ferriol ${ }^{5}$, que ya en el Digesto puede leerse que "nadie es señor de sus miembros", disposición ésta que -a decir de los autores citados- priva a la persona de la facultad de disponer libremente de las partes de su cuerpo y, con mayor motivo, de la vida, "por

${ }^{3}$ De Castro, Temas de derecho civil, Madrid, 1972, p. 10.

${ }^{4}$ Villary, La pensée juridique, París, 1960, p. 56, citado por Braud, La notion de liberté publique en droit français, Paris, 1968, p. 229.

${ }^{5}$ Puig Brutau y Puig Ferriol, Fundamentos de derecho civil, t. 1, Vol. 1, Primera parte: Parte general. Sujeto y objeto del derecho, Barcelona, 1979, p. 113. 
cuanto, con ello -señalan-, se transmuta la esencia misma de la persona, puesto que, de sujeto de derechos, pasa a convertirse en una cosa mueble, cual es el cadáver".

Tampoco respecto de las libertades cabe hablar de derechos subjetivos perfectos, sino y cuando más de derechos "reflejos" también, de derechos "difusos", "limitados" o ni tan siquiera eso, si seguimos las enseñanzas de Carbonnier, lo cual es aconsejable por regla generalísima.

Carbonnier ${ }^{6}$ distingue los derechos de la personalidad -que entiende como una serie de prerrogativas suficientemente precisas en relación con su objeto- de las libertades civiles, que coloca al lado de los derechos de la personalidad, más separadas de ellos.

La libertad civil -para el maestro francés- es la posibilidad reconocida a la persona de hacer cuanto le plazca, de poder actuar según su libre albedrío. En su opinión, la misma carece de un objeto lo suficientemente preciso como para constituir un derecho subjetivo, en el sentido técnico del término. La libertad -añade Carbonnier, que es un liberal-, más que un derecho subjetivo, es una virtualidad de derecho, como dice Josserand. La libertad se define por sus límites necesarios, se detiene ante la libertad de los otros y, sobre todo, ante los derechos ajenos.

\section{LOS DERECHOS DE LA PERSONALIDAD SOBRE LOS BIENES SOCIALES E INDIVIDUALES Y LOS CARACTERES PREDICABLES DE LOS MISMOS (EL ASUNTO en la Ley Orgánica 1/1982)}

Por cuanto queda dicho, los derechos de la personalidad, entendidos como verdaderos y propios derechos subjetivos constituidos por un haz unitario de facultades cuyo ejercicio y defensa se encomienda a su titular, son predicables, propiamente y sólo, de los bienes sociales e individuales y cuentan con una serie de caracteres que la doctrina les ha venido asignando y que, en los últimos tiempos, han sido revisados críticamente.

Los caracteres asignados de antiguo son los siguientes: derechos originarios e innatos, inherentes a la persona, individuales, privados, absolutos, indisponibles, intransmisibles, irrenunciables, inexpropiables e inembargables, imprescriptibles en fin. La revisión crítica de tales caracteres, con un algo de decimonónicos, no es ajena a las ideas de función social de los derechos, a la de prohibición del abuso de los mismos y a la que predica

${ }^{6}$ Carbonnier, Droit civil, 1, París, p. 250ss. 
la bondad de señalar, en ocasiones, límites al ejercicio de aquéllos, en aras de la buena fe o de su colisión con otros.

La revisión ha llevado a decir cosas como las siguientes:

- Los derechos de la personalidad son derechos absolutos o de exclusión en el sentido de su oponibilidad erga omnes, mas no son absolutos en cuanto a su contenido, pues "están condicionados - sentaba, entre otros, don José Castán $-^{7}$ por las exigencias del orden moral y las del orden público, que obligan a ponerlos en relación con los derechos de los demás hombres y los imperativos del bien común".

- Hay ciertas excepciones a la regla de la indisponibilidad, de la intransmisibilidad, resultantes de normas como las que permiten los trasplantes de órganos de personas vivas o los negocios en torno a la propia imagen de éstas.

- La imprescriptibilidad de los derechos, en fin, puede verse limitada, de hecho, por la prescripción, posible, de las acciones destinadas a protegerlos.

La tensión doctrinal, que acabamos de señalar, respecto de los caracteres asignables a los derechos de la personalidad tiene su fiel reflejo en el articulado de la Ley Orgánica 1/1982, de 5 de mayo, de protección civil del derecho al honor, a la intimidad personal y familiar y a la propia imagen.

En efecto y aun cuando el artículo 1.3 de dicha ley empieza diciendo que tales derechos son irrenunciables, inalienables e imprescriptibles y que la renuncia a la protección prevista para los mismos en la ley dicha será nula, acto seguido matiza que todo lo anterior queda dicho "sin perjuicio de los supuestos de autorización o consentimiento a que se refiere el artículo 2 de esta Ley".

Dicho artículo 2, en su apartado 1, sienta que la protección civil de los derechos que venimos considerando "quedará delimitada por las leyes y por los usos sociales, atendiendo al ámbito que, por sus propios actos, mantenga cada persona reservada para sí misma o su familia”. El ámbito dicho, a lo que parece, puede ser mayor, menor, ínfimo o, incluso, inexistente, quedando la amplitud concreta del mismo al arbitrio de cada uno.

A mayor abundamiento y a decir del apartado 2 del artículo 2: "No se apreciará la existencia de intromisión ilegítima en el ámbito protegido cuando estuviere expresamente autorizada por la Ley -hablando de

${ }^{7}$ Castán Tobeñas, "Los derechos de la personalidad", RGLJ, 1952, julio-agosto, p. 5ss; en particular, p. 22. 
intromisiones legítimas el artículo 8 de la que venimos comentando- o cuando el titular del derecho hubiere otorgado al efecto su consentimiento expreso." Esta última afırmación pone en tela de juicio la irrenunciabilidad y la imprescriptibilidad a ultranza de los derechos, y ello a pesar de que el apartado 3 del artículo 2 citado establece que el consentimiento dicho es revocable en cualquier momento, pues puede, muy bien, no haber, de hecho, revocación y, para que la haya, el renunciante ha de cumplir con una carga, que puede ser pesada y le fija el apartado 3 referido in fine; a saber, la indemnización de los daños y perjuicios causados, incluyéndose en ellos -expresamente por la ley y a mayor abundamiento- las expectativas justificadas de quien haya de soportar la renuncia.

La imprescriptibilidad de los derechos, en fin, es puesta en tela de juicio, a la postre, en el artículo 3.3 de la Ley Orgánica 1/82, artículo que, hablando del ejercicio de acciones de protección civil de los derechos que venimos considerando con posterioridad al fallecimiento del titular de los mismos, legitima, en ocasiones, al Ministerio Fiscal, "que podrá actuar -se dice- de oficio o a instancia de persona interesada, siempre que no hubieran transcurrido más de ochenta años desde el fallecimiento del afectado". No puede, pues, actuar después. "El mismo plazo se observará -termina diciendo el artículo 3- cuando el ejercicio de las acciones mencionadas corresponda a una persona jurídica designada en testamento."

La imprescriptibilidad de los derechos de la personalidad -que poco o nada son, desprovistos de acciones que los protejan de las agresiones ajenas- es puesta en tela de juicio, también y a la postre, por el artículo 9.5 de la Ley Orgánica que venimos considerando, artículo que reza así: "Las acciones de protección frente a las intromisiones ilegítimas caducarán transcurridos cuatro años desde que el legitimado pudo ejercitarlas."

\section{LOS DERECHOS DE LA PERSONALIDAD COMO CATEGORÍA Y LOS ANTECEDENTES DE LA MISMA}

Los derechos de la personalidad, entendidos como verdaderos y propios derechos subjetivos, van viendo la luz a partir de la segunda mitad del siglo xix, lo cual es lógico, cuando no obligado, dado que la categoría genérica misma de derecho subjetivo - de la cual son especie singular- surge en el siglo dicho, lo cual no impide -entiéndase bien- que antes no fuesen protegidos los bienes que constituyen el objeto de los mismos.

En efecto y ya en el derecho romano -sistema jurídico de acciones, más 
que de derechos- encuentra acomodo, a decir de Bonafante ${ }^{8} \mathrm{y}$ al lado de la actio legis Aquiliae, pensada para lograr la indemnización de daños extracontractuales de índole patrimonial, la actio iniuriarum. "Injuria (iniuria), en sentido propio y a decir del maestro italiano, es un acto que lesiona, física o moralmente, o sea, en honor, a la persona misma. Puede consistir en palabras (verbis) o en hechos (re); puede ser grave, o sea cualificada por circunstancias agravantes de persona, lugar o tiempo, o simple. [...] Se distingue también la injuria inmediata, o sea causada directamente a la persona, y la mediata, o sea hecha a personas unidas íntimamente con ella -por ejemplo, a la novia, a la hija, etcétera-. En virtud de esto, varias personas pueden tener cumulativamente derecho a ejercitarla. [...] Las duras penas establecidas - al respecto- por las XII Tablas -entre ellas, la del Talión- dieron lugar a la actio iniuriarum aestimatoria, introducida por el Pretor y en base a la cual la pena se hizo pecuniaria, sometiendo la medida o aestimatio frecuentemente al recto criterio (arbitrium) del Juez."

En suma, diversas acciones en clave de daño extracontractual y una específica para los supuestos de daños morales, riqueza de matices que no llegamos a tener nosotros, con una sola acción ex 1902 del Código Civil durante muchos años y la enemiga, durante muchos también, de aceptar, en el seno del mismo, la indemnización del daño moral, aceptación que se produce, en pleno siglo xx ya, por obra y gracia de la jurisprudencia, abriendo paso ello -a decir del profesor De Castro- ${ }^{9}$ a la consideración y protección jurídica de los bienes de la personalidad en general. No es justo, por consiguiente, que Donello -en el siglo xvI y según nos indica Oliveros Lapuerta- ${ }^{10}$ haya reprochado a los jurisconsultos romanos el haber olvidado los derechos de la persona, dado el interés prestado por los mismos a los bienes objeto de aquéllos y a las acciones tendentes a reparar el daño que pudieran sufrir.

Como no podía ser menos y nos recuerda De Castro, ${ }^{11}$ la pauta romana está en las Partidas, Partidas que, a imagen y semejanza de la actio iniuriarum aestimatoria, establecen $-7,9,21$ - que la indemnización de los daños causados a los bienes de la personalidad, de los daños morales, ha de ser "enmienda en pecho de dineros".

${ }^{8}$ Bonfante, Instituciones de derecho romano, traducción de la octava edición italiana hecha por Luis Bacci y Andrés Larrosa, quinta edición, Reus, Madrid, 1979, p. 532.

${ }^{9}$ De Castro, Temas, Op. cit., p. 8ss.

${ }^{10}$ Oliveros Lapuerta, Estudio sobre la Ley de protección civil del derecho al honor, a la intimidad personal y familiar y a la propia imagen, Cuadernos de Documentación, No. 38, Presidencia del Gobierno, Madrid, 1981, p. 14.

${ }^{11}$ De Castro, Temas, loc. ult. cit. 
La protección de los bienes de la personalidad existe, como se ve, aunque se arbitre por la vía de las acciones, más que por la de los derechos subjetivos.

De los bienes de la personalidad se ocupó también y como sabemos Santo Tomás y se ocuparon, asimismo y muchos años más tarde, comentaristas españoles suyos tan prestigiosos como Vitoria, Soto o Molina que, con todo y como juristas-filósofos que eran, los vieron desde el prisma del pecado, del delito y de la pena, del mismo modo que en 1604 Gómez de Amescua ${ }^{12}$ los vio, en el Palermo español, desde una perspectiva política.

La perspectiva filosófica -que no civil-y la perspectiva política del tratamiento de los bienes de la personalidad nos acercan a los derechos humanos y a los derechos fundamentales también que, como categorías y cual veremos, preceden en el tiempo a los derechos de la personalidad y tienen semejanzas con ellos, amén de tener diferencias.

\section{Derechos humanos, Derechos fundamentales Y DERECHOS DE LA PERSONALIDAD}

Por cuanto a los primeros respecta y con Truyol, ${ }^{13}$ cabe decir lo siguiente: el tema de los derechos humanos, en sus orígenes, tiene mucho que ver con la intolerancia -magistralmente retratada por Griffith en una película mítica y de ese título, precisamente, que lo llevó a la ruina-y las guerras de religión, pues, no en vano y a lo largo de los siglos xVII y xVIII el problema del derecho a la libertad religiosa y de conciencia -suscitado, en Francia, por los calvinistas- fue asociándose al problema de los derechos civiles y políticos en general. El tema de los derechos humanos no implica una tensión particular/particular ni, tampoco y necesariamente, una tensión ciudadano/Estado. El tema de los derechos humanos tiene, en muy buena medida, un emplazamiento inicial filosófico, amén de unas garantías efectivas escuálidas, cuando no inexistentes - al margen del aspecto revolucionario e innovador de las Declaraciones de derechos, que propician el tránsito hacia los derechos humanos "constitucionalizados", hacia los derechos fundamentales de los ciudadanos, dotados de garantías tangibles.

Y es que el problema de los derechos humanos no está en citarlos -hay elencos cuantiosos de los mismos en documentos regionales e internacionales y universales, como es sabido- sino en hacer que sean respetados,

\footnotetext{
${ }^{12}$ Gómez de Amescua, Tractatus de potestate in se ipsum, Palermo, 1604.

${ }^{13}$ Truyol, Los derechos humanos, Madrid, 1982, p. 11ss.
} 
lo cual no suele suceder cuando los derechos son sólo "humanos" y su protección se fía a la benevolencia de los más fuertes, providencia divina al margen.

En el sentido indicado, dice Bobbio: ${ }^{14}$ "El problema grave de nuestro tiempo respecto de los derechos humanos no es el de fundamentarlos, sino el de protegerlos... El problema que se nos presenta, en efecto, no es filosófico, sino jurídico y, en sentido más amplio, político. No se trata tanto de saber cuáles o cuántos son estos derechos, cuál es su naturaleza y fundamento, si son derechos naturales o históricos, absolutos o relativos, sino cuál es el modo más seguro para garantizarlos, para impedir que, a pesar de las declaraciones solemnes de los mismos, sean continuamente violados."

Las garantías - por el contrario y aunque, excepcionalmente, puedan limitarse o suspenderse- son ingrediente indispensable de los derechos fundamentales -que tienen por objeto, en ocasiones, los mismos bienes que los humanos- mas son consagrados en las constituciones de los estados a partir del siglo XIX, aparejándose a los mismos acciones, procedimientos y normas que facilitan, agilizan y refuerzan la protección de los mismos, consolidando un núcleo de defensa del ciudadano, de su personalidad y de sus libertades, frente a los poderes del Estado.

Como dice Aubert, ${ }^{15}$ cuando la Constitución proclama una libertad pública -cuando proclama un derecho fundamental- lleva a cabo una especie de reparto de competencias entre el Estado y los individuos; traza, en torno a las personas privadas, un círculo que declara infranqueable -en principio- por los poderes públicos. Las amenazas a las libertades y a los derechos procedentes de otros particulares no se contemplan en la Constitución, sino en leyes penales -en casos extremos- y en leyes civiles -en la normalidad de los casos-, incardinándose en el derecho civil a partir de la segunda mitad del siglo xIx los derechos de la personalidad que, entonces, ven la luz.

Y es que, como dice Ricardo de Ángel: ${ }^{16}$ "Sólo cuando la persona ha conseguido un mínimo de seguridad frente al Estado, frente al poder, desplaza sus preocupaciones al terreno de las relaciones privadas.” Es así que, al margen de precedentes anteriores -que conocemos- y cual señala

${ }^{14}$ Norberto Bobbio, "Presente y porvenir", Op. cit.

${ }^{15}$ Aubert, Traité de Droit constitutionnel suisse, 11, Neuchatel, 1967, p. 627ss.

${ }^{16}$ De Ángel, "Protección de la personalidad en el derecho privado", RDN, enero-marzo, 1974, p. 7ss, en particular, p. 25. 
don José Beltrán de Heredia, ${ }^{17}$ "los derechos de la personalidad en sentido técnico, es decir, entendidos como protección de la libre actuación de la persona como tal -frente a otras personas, habría que precisar- son una conquista del siglo xix."

Más concretamente y a decir del señor Decano Carbonnier, ${ }^{18}$ la noción de los "derechos de la personalidad" es de origen germánico, introduciéndose en Francia a través de la obra del suizo Roguin titulada Las reglas jurídicas, publicada el año 1889 en Lausana y de la que existe una traducción española debida a José María Navarro de Palencia y editada en Madrid. Tal noción, a decir siempre de Carbonnier, se consolida, después, en el país vecino por mediación de autores como Boistel (Filosofía del derecho, 1889), Perreau (“Los derechos de la personalidad", 1909) y Nerson (Los derechos extrapatrimoniales, tesis leída y publicada en Lyon el año 1939).

Por lo que a Alemania se refiere y sin olvidar a Puchta y a Windscheid, parecen ser Kohler y Gierke -contemporáneos de Jellinek- los autores que rompen sus lanzas a favor del reconocimiento de derechos de la personalidad o derechos sobre la propia persona. Gierke -no se olvide- publica el tomo I de su Derecho privado alemán en el año 1895, publicando Kohler sus trabajos por esas fechas.

En Italia ha de hacerse referencia a Campogrande -autor de un trabajo titulado "Los derechos sobre la propia persona" que publicó nuestra nunca suficientemente bien ponderada Revista General de Legislación y Jurisprudencia en 1896-, a Chironi y, sobre todo, a Fadda y Bensa, comentaristas y anotadores de Windscheid.

En España y como Ricardo de Ángel nos recuerda, ${ }^{19}$ los civilistas españoles del XIX no se ocuparon del tema de los derechos de la personalidad. Incluso parecía verse la categoría con cierta desconfianza, hecho que explicaría la nota que la Revista General inserta al final del artículo de Campogrande a que me he referido, nota que dice así: "La Dirección de la Revista no se halla conforme con las ideas expuestas en el artículo inserto por tan notable escritor jurídico, si bien juzga oportuno darle a conocer a sus abonados." Si no me equivoco, dirigía la revista entonces nada menos

\footnotetext{
${ }^{17}$ José Beltrán de Heredia, Construcción jurídica de los derechos de la personalidad, Madrid, 1976, p. 31.

${ }^{18}$ Carbonnier, Droit civil, 1, París, p. 258.

${ }^{19}$ Ricardo de Ángel, "Protección de la personalidad en el derecho privado", RDN, enero-marzo, 1974, p.7 ss; la cita corresponde a la página 125 .
} 
que don José María Manresa y Navarro, diputado, senador, subsecretario de Gracia y Justicia, fiscal, magistrado del Tribunal Supremo, vocal de la Comisión de Códigos durante la gestación del Civil y, sobre todo, primer y mejor comentarista del que, durante muchos años, fue llamado nuestro primer cuerpo legal. Yo, que con menos merecimientos y en compañía de Joaquín Rams, la dirijo ahora, no comparto, en el xxI, la opinión del maestro Manresa, por mucho que ésta pudiera parecer plausible en el XIX.

Bien iniciada ya la primera mitad del xx y por cuanto me resulta, aparecen los primeros autores, los primeros civilistas que se ocupan, siquiera sea sucintamente, de los bienes y derechos de la personalidad, haciendo referencia expresa, al hacerlo y por cierto, a Kohler y Gierke. Se trata, en primer lugar de Valverde, catedrático y rector de Valladolid, amén de autor de un Tratado de derecho civil español cuya primera edición data de 1909. Se trata, en segundo término, de Sánchez Román, que escribe, por las mismas fechas, la Parte general de sus Estudios de derecho civil. Se trata, en tercer término y sobre todo, de Clemente de Diego, cuya Parte general del Curso elemental de derecho civil español común y foral está fechada en el Madrid de 1923.

Desgraciadamente, las tesis de Clemente de Diego sobre los derechos de la personalidad, tesis dotadas de mucha modernidad, no se consolidan en la doctrina patria, como lo demuestra el hecho de que, bastantes años más tarde, en 1943, Pérez y Alguer han de recurrir -como antes había hecho Valverde- al artículo 1902 del Código Civil y a la indemnización por daño moral para justificar, de algún modo, la existencia de bienes y derechos de la personalidad, carentes, aún, de asentamiento preciso en la parte general del derecho civil, si bien es verdad que Pérez y Alguer se ven, de algún modo, obligados a seguir la pauta del texto contenido en la Parte general del Tratado de derecho civil de Enneccerus y Nipperdey, texto que traducen y comentan.

En suma y con la salvedad representada por Clemente de Diego, hay que esperar a don José Castán -que también y tan bien dirigió la Revista General- y al comienzo de la segunda mitad del siglo xx para tener, en España, una visión moderna y actual de los derechos de la personalidad, manifestada en el trabajo titulado Los derechos de la personalidad que se publicó, precisamente, en las páginas 5 y siguientes del número correspondiente a julio y agosto de 1952 de la dicha Revista General. Las ideas allí expresadas son trasladadas a un capítulo específico destinado a los derechos de la personalidad, dentro del volumen segundo de la octava edi- 
ción de la Parte general de su Derecho civil español, común y foral, octava edición fechada asimismo en el Madrid de 1952.

Ahora bien, por encima de los avatares históricos y de los emplazamientos fluctuantes dentro de la disciplina, una cosa es cierta: el tema de los bienes y derechos de la personalidad es tema de derecho civil que implica tensión entre particulares y ello lo distingue -como hemos de ver y por diversas razones- de los derechos humanos y de los derechos fundamentales.

\section{Diferencias entre las categorías antes citadas}

- Las categorías antes dichas tienen, como hemos visto y teniendo objetos similares, cuando no idénticos, orígenes históricos diversos, que permiten hablar, en primer lugar, de derechos humanos y, después, de derechos fundamentales $\mathrm{y}$, por último, de derechos de la personalidad.

- Las categorías antes dichas tienen emplazamientos diferenciados dentro del derecho, incardinándose los derechos humanos en la filosofía del derecho o el derecho internacional, los fundamentales en el derecho constitucional y los de la personalidad, fundamentalmente, en el derecho civil.

- Las categorías antes dichas se mueven en ámbitos no exactamente coincidentes. Así, los bienes y derechos de la personalidad se mueven en un ámbito más reducido -amén de distinto, en ocasiones- que el señalado a los derechos humanos o a los derechos fundamentales.

En efecto y por lo que a los derechos humanos respecta, tanto en las clasificaciones de los mismos propuestas por la doctrina como en las contenidas en las declaraciones internacionales, hay un amplio y, en ocasiones, variopinto elenco de derechos muchos de los cuales -derechos procesales y políticos y relativos a ciertas libertades- nada tienen que ver con los clásicos derechos de la personalidad.

Comparando, por otra parte, derechos fundamentales y derechos de la personalidad y utilizando terminología de Eduardo García de Enterría y Tomás Ramón Fernández, ${ }^{20}$ los derechos de la personalidad vendrían a corresponderse con las que ellos -siguiendo pautas de los status acuñados por Jellinek $-{ }^{21}$ llaman libertades-autonomía y distinguen tanto de los derechos cívicos o políticos -o libertades-participación- como de los derechos económicos o sociales, o derechos-prestación.

${ }^{20}$ García de Enterria, y Fernández, Curso de derecho administrativo, 11, Madrid, 1982, p. 55ss.

${ }^{21}$ Jellinek, Sistema dei diritti pubblici subjettivi, traducción italiana, Milán, 1912, p. 96ss. 
Una cosa es cierta: dentro de los derechos de la personalidad y por muy ampliamente que se formule el elenco de los mismos, no tienen cabida todos aquellos que, desde otra perspectiva, son considerados como derechos fundamentales o, en otra terminología y llegando el caso, como libertades públicas. Como resulta patente y además de aquellos que tuvieran objeto coincidente con los derechos de la personalidad, hay muchos otros derechos y muchas otras libertades en nuestra Constitución que, sin embargo, carece de una referencia específica a la fama, como bien distinto del honor sobre el que pueden recaer derechos, siendo más que discutible que en el artículo 20.1.b) de la misma encuentre acomodo el llamado derecho moral de autor y obvio que no se habla, en aquélla, del derecho a la identidad personal, dentro del cual se han encuadrado cuestiones tales como el nombre, los apellidos, los seudónimos y los títulos nobiliarios.

Derecho a la fama, derecho moral de autor y derecho a la identidad personal, todos ellos encuadrables en los derechos de la personalidad. Ámbito diverso, pues, y no exactamente coincidente entre los distintos derechos, como ha quedado dicho.

- Incluso cuando el bien protegido es el mismo y como hemos apuntado ya, la perspectiva es distinta según se trate de derechos de la personalidad o de derechos fundamentales. Como dice Carbonnier, ${ }^{22}$ al referirse a los atributos de la persona física, "bajo esta fórmula se comprenden ciertas prerrogativas que pertenecen a toda persona "comme par droit de naissance'; una especie de derechos del hombre, en el sentido de la Declaración de 1789, pero en el plano del derecho privado, que no en el derecho público; derechos del hombre oponibles a otros hombres, no siendo asunto propio del derecho civil el oponerlos al Estado. La teoría civilista de los derechos de la personalidad -sienta el gran maestro francés- juega exclusivamente en las relaciones entre particulares".

En la misma línea, es muy clarificador el siguiente texto de Tomás de la Quadra-Salcedo:23 "Todo derecho fundamental consiste en un derecho subjetivo reforzado... Ahora bien, ese derecho fundamental es, además, un derecho subjetivo como cualquier otro... El que un determinado interés o posición subjetiva se proteja frente al legislador y frente a la Administración y el que, en esa protección, adquiera su carácter fundamental, no significa que, frente a los demás, frente a los particulares no exista; existe

${ }^{22}$ Carbonnier, Droit civil, 1, París, 1971, p. 250.

${ }^{23}$ De la Quadra-Salcedo, El recurso de amparo y los derechos fundamentales en las relaciones entre particulares, Madrid, 1981, pp. 66-67. 
como un derecho subjetivo más, aunque, en todo caso, prevalente."

- Por lo dicho y aun tomando como punto de referencia unos mismos bienes protegidos, cabe hablar, respecto de ellos, de distintos tipos de protección y garantías, compatibles entre sí, en el ámbito estricto del ordenamiento jurídico español.

Hay, en primer lugar, una protección, una garantía constitucional plasmada en diversos artículos de la Constitución y de leyes que la desarrollan, como la Ley Orgánica 3/81, de 6 de abril, del Defensor del Pueblo o la Ley Orgánica 2/79, de 3 de octubre, del Tribunal Constitucional.

Hay, además, una protección, una garantía penal, contenida en diversos artículos del Código del mismo nombre.

Hay, a mayor abundamiento, una garantía administrativa, en la que pueden incluirse los derechos de réplica y de rectificación, tratados en la Ley Orgánica 2/84, de 26 de marzo.

Hay, en fin, una garantía civil, que gira en torno al artículo 1902 del Código del mismo nombre y, más singularmente, en torno a la Ley Orgánica $1 / 1982$, que ya conocemos.

Hay, en fin, una especifica garantía jurisdiccional civil, comprendida dentro de las previstas en la Ley 62/1978, de protección jurisdiccional de los derechos fundamentales.

Ello hace, en mi opinión y en la de muchos otros, que, en el caso de violaciones de bienes o derechos de la personalidad realizadas por particulares, no quepa el recurso de amparo constitucional ante el tribunal del mismo nombre - pensado para otros menesteres-, como no cabe tampoco, en tales casos, el acudir en queja al defensor del pueblo ni el que éste inicie una investigación de oficio sobre el particular, cual se deduce de la lectura de los artículos 1 y 9.2 de la Ley Orgánica 3/81, del defensor del pueblo.

No creo, por consiguiente, en la posibilidad de lo que -usando la propia y genuina terminología alemana- ha dado en llamarse unmittelbare Drittwirkung o eficacia inmediata de los derechos fundamentales en las relaciones entre particulares, aceptando, tan sólo y en su caso, la mittelbare Drittwirkung o eficacia mediata de tales derechos en tales relaciones o, en terminología distinta y consecuencias prácticamente idénticas, la Ausstrahlungskraft o fuerza de irradiación de los derechos dichos en las relaciones señaladas. Ésta es, por otra parte y por cuanto me resulta, la creencia generalizada en Alemania sobre el particular, tanto en la doctrina como en la jurisprudencia, incluida la del Tribunal Constitucional de dicho país.

No cabe, en fin, que en el ámbito estricto de las relaciones entre parti- 
culares, pueda pensarse en una supresión o privación de los derechos de la personalidad, a diferencia de lo que puede suceder, llegado el caso, con derechos fundamentales o libertades públicas con objetos idénticos a los de alguno de aquéllos.

\section{LA ACTUALIDAD DE LOS DERECHOS DE LA PERSONALIDAD Y SU COLISIÓN CON LAS LIBERTADES DE EXPRESIÓN E INFORMACIÓN}

Los derechos de la personalidad, con las características propias y singulares que hemos venido identificando, gozan en la actualidad de enorme predicamento y respeto, lo cual no impide el que, en muchas ocasiones y en nombre de las libertades de expresión e información -altamente valoradas en los tiempos inmediatamente posteriores a la Constitución, en contrapartida a lo poco que lo habían sido en otros-, tales derechos se vean afectados más allá de las intromisiones legitimas permitidas por la Ley Orgánica 1/82 de protección civil de los mismos.

Se produce, entonces, una tensión entre los derechos y las libertades dichas, una pretendida colisión entre unos y otras, asunto de mucha importancia en el que ha terciado, como no podía ser menos, el Tribunal Supremo, asunto en el que ha terciado también y con criterios no siempre coincidentes con el primero, el Tribunal Constitucional.

Yo he estudiado la jurisprudencia del uno y del otro y el parecer de los autores sobre la materia ${ }^{24} \mathrm{y}$ creo lo siguiente al respecto:

En el caso de colisión entre derechos y libertades no es de aplicación una reducción proporcional de unos y otras, colocados todos a nivel de igualdad, ni es procedente un "balanceo" ni una ponderación de ambos para decidir lo que haya de hacerse. En el caso de colisión pretendida entre unos y otras, privan los primeros sobre las segundas, por ser jerárquicamente superiores a ellas tanto en el ámbito constitucional como en el estrictamente civil, que es, dicho sea de paso, el ámbito en el que se plantean los conflictos.

Tal opinión mantiene nuestro Tribunal Supremo y, a la postre y también -con menos virulencia- el Tribunal Constitucional, si bien, en los primeros tiempos de su actuación y en defensa de las libertades recién

${ }^{24}$ Rogel Vide, Bienes de la personalidad, derechos fundamentales y libertades públicas, Bolonia, 1985; y también "El derecho al honor, a la intimidad personal y familiar y a la propia imagen y las libertades de expresión e información en la jurisprudencia del Tribunal Supremo y en la del Tribunal Constitucional”, en Estudios de derecho civil en homenaje a Lacruz, Vol. 11, Barcelona, 1993, p. 1913ss. 
estrenadas, llegó a sostener lo contrario, siguiendo pautas norteamericanas importadas por algunos autores patrios sin tener en cuenta que nosotros carecemos de enmiendas a la Constitución en las que se encumbre la libertad de expresión, gozando de artículos como el 20.4 en el que, expresa y tajantemente, se afirma: "Estas libertades -entre las que se encuentran las de expresión e información - tienen su límite en el respeto a los derechos reconocidos en este Título, en los preceptos de las leyes que los desarrollen y, especialmente -en línea con el sentir del pueblo español, no necesariamente coincidente con el sentir de otros-, en el derecho al honor, a la intimidad, a la propia imagen y a la protección de la juventud y de la infancia."

Explica muy bien la cuestión mi buen amigo Luis Humberto Clavería cuando apunta ${ }^{25}$ que, en principio, el conflicto entre libertades y derechos se resuelve a favor de los segundos, lo cual no impide que el ámbito de protección de éstos se estreche en presencia del ejercicio de aquéllas, como se infiere del artículo 8 de la Ley Orgánica 1/82, a decir del cual y con carácter general, no se reputarán intromisiones ilegitimas en los derechos protegidos las actuaciones autorizadas o acordadas por la autoridad competente de acuerdo con la ley, ni aquellas en las que predomine un interés histórico, científico o cultural relevante. Dicha regla general es explicada así por Clavería: si bien la libertad de expresión e información halla su límite en el respeto al honor y a la intimidad de los demás, es conforme a derecho dañar dicho honor o dicha intimidad si el interés público lo requiere, pero $-\mathrm{y}$ aquí está el matiz crucial- sólo hasta la medida en que lo requiera.

No se olvide, por otra parte y en justa contrapartida, que la libertad de información, en su correcto ejercicio y como nos recuerda María Jesús Blanco Quintana, ${ }^{26}$ ha de versar sobre hechos noticiables, de trascendencia pública, habiendo de ser ciertas las noticias facilitadas, veracidad que no se requiere para las opiniones manifestadas y juicios de valor emitidos al amparo de la libertad de expresión. En cualquier caso, ni el ejercicio de una libertad ni el de la otra justifica el empleo de términos insultantes o vejatorios.

\footnotetext{
${ }^{25}$ Clavería Gosálvez, "Reflexiones sobre los derechos de la personalidad a la luz de la Ley Orgánica 1/82, de 5 de mayo", $A D C, 1983$, p. 1243ss.

${ }^{26}$ Blanco Quintana, "El derecho al honor y las libertades de expresión e información en la jurisprudencia del Tribunal Constitucional", Revista de la Facultad de Derecho de la Universidad Complutense de Madrid, número 93 (Anuario), p. 49ss; la cita corresponde a la página 70.
} 
Decir, en otro orden de cosas y con pautas de comportamiento correctas en la mano, que difícilmente los derechos de la personalidad -entendidos en sus justos términos y sabidos los límites que ayudan a definirlos- pueden determinar impedimentos o trabas a las libertades de expresión e información -más bien pensadas a favor del ciudadano y frente a los poderes públicos-, del mismo que difícilmente el recto ejercicio de dichas libertades -sensacionalismos aparte- puede lesionar los derechos cuyo estudio nos ocupa y a los casos juzgados por los tribunales me remito, para acreditar la bondad de las afırmaciones precedentes.

\section{HONOR, PERSONAS JURÍDICAS Y PUBLICIDAD}

En realidad, plantearse el tema del honor de las personas jurídicas es un contrasentido pues, en puridad, el honor, en cuanto valoración de uno mismo, en cuanto sentimiento, sólo puede ser propio de las personas físicas. Otra cosa es la fama, lo que los demás piensan de una persona o institución, con hipotéticas repercusiones económicas en empresas, colegios, corporaciones, productos o servicios, fama que puede predicarse, sin dificultad, de las personas jurídicas, de las empresas, hablándose, entonces, de renombre, de buen nombre, de prestigio, de reputación.

El honor y la fama no son exactamente coincidentes, como ha quedado apuntado ya. Una persona puede ser honorable, tener un alto concepto de sí mismo y un código moral que respetar sin ser famoso ni quererlo. Por el contrario, una persona puede ser famosa, siendo deleznable y gozando, con toda justicia, de mala fama.

Los especialistas en derechos de la personalidad distinguieron entre honor y fama, mas la Constitución y la Ley Orgánica 1/82 no lo hicieron, lo cual lleva a los tribunales a predicar un concepto de honor lo suficientemente amplio como para comprender, en su seno, a la fama, aunque ello no sea enteramente ortodoxo.

Se habla, así, del aspecto subjetivo del honor -que se identifica con el sentimiento de la propia dignidad-y también del aspecto objetivo del mismo -que se identifica con la estimación ajena-, aspecto, este último, referible a las personas jurídicas.

Al honor en sentido objetivo, cuando no a la fama, parecen hacer referencia los números 3 y 7 del artículo 7 de la Ley Orgánica 1/82, al considerar intromisiones ilegítimas, respectivamente, "la divulgación de hechos relativos a la vida privada de una persona o familia que afecten a su reputación o 
buen nombre" y "la divulgación de expresiones o hechos concernientes a una persona cuando la difame o la haga desmerecer en la consideración ajena".

El campo de acción del honor -de la fama, si se quiere- en relación con las personas jurídicas ha sido ampliado al de la publicidad denigratoria respecto de las mismas en una tesis doctoral, interesante e inédita, de la que es autor José Sánchez Parra y director Carlos Lema Devesa. La lectura de la misma, calificada de apto cum laude por un tribunal del que formé parte, tuvo lugar el día 27 de septiembre de 2001 y, en la exposición como en el texto, el doctorando defendió la bondad de traer a colación el derecho al honor y la indemnización por daños morales en el campo de la publicidad denigratoria como único medio para lograr, además de la cesación de tal actividad, propugnada por las normas relativas a publicidad y competencia desleal, el resarcimiento de los perjuicios causados, de los daños emergentes y de los lucros cesantes también.

La tesis interesó al tribunal hasta tal punto que, en el seno del mismo, se produjeron opiniones divergentes sobre algunos particulares. En opinión, así, de los profesores Galán y De la Cuesta, la publicidad denigratoria y las normas especiales que la castigan y a las que habrá que estar, persiguen que el mercado no sea alterado, que no sea distorsionado torticeramente, interés público superior al privado de los empresarios a mantener su reputación, razón por la cual el recurso de las normas reguladoras de los bienes de la personalidad -si es posible- ha de hacerse con mucha cautela, dada la existencia de normas mercantiles específicas contra la publicidad denigratoria.

Distinta -amén de más galaica- era la opinión de Otero Lastres y de un servidor de ustedes, al entender que lo primordial es la protección del buen nombre del empresario y no tanto el mantenimiento de un mercado impoluto, cual demuestra el hecho de que no estén previstas actuaciones de oficio contra la publicidad denigratoria, estando, a la postre, en manos del perjudicado el actuar contra la misma, perjudicado que puede muy bien no hacerlo, ya sea porque menosprecia la tal publicidad - no hay mayor desprecio que no hacer aprecio- ya sea porque, sin despreciarla, juzga que, a la postre, el propio mercado y los consumidores pondrán a cada uno en su sitio y volverán la publicidad denigratoria contra quien la hizo.

En todo caso, una cosa es cierta: el campo de acción del honor se amplía a las personas jurídicas y a todas las actividades que giran en torno a las mismas, incluida -y es novedoso, por mucho que ello se discuta- la publicidad denigratoria, del modo y manera que ha quedado dicho. 


\section{Derechos de la personalidad y derecho moral de autor}

Es por todos sabido que el autor de una obra del espíritu tiene, sobre la misma, facultades de índole patrimonial como las de distribución y comunicación pública; es por todos sabido también que, al margen de las mismas y aunque se hayan cedido éstas, el autor tiene y se reserva facultades de índole moral sobre la obra en cuestión, cual las de inédito, paternidad e integridad.

Autores sobresalientes -De Castro, Castán- han sostenido que dichas facultades integran un derecho moral incardinable, con todo merecimiento, dentro de los clásicos derechos de la personalidad.

Otros autores igualmente sobresalientes -Beltrán, Lacruz- han sostenido, por el contrario, que, aun siendo personalísimo y de ejercicio muy restringido, el derecho de autor no es incardinable dentro de los derechos referidos.

Fundamentando tal afirmación, decía don José Beltrán de Heredia, en su discurso de ingreso en la Academia:27 "Los derechos de autor, en sus diversas manifestaciones, implican una exteriorización que no afecta al ingenio en sí, ni a la posibilidad o libertad de su actuación, sino a sus expresiones concretas. Suponen una creación que, como la literaria o la artística, salen fuera de nuestro ser personal.”

En la misma línea y muy bellamente, señalaba Lacruz:28 "El autor, en cada obra intelectual que saca a la luz, no incorpora algo a su persona, sino que acrece su circunstancia; es decir, cada obra supone una proyección adicional de la subjetividad, que no es parte de tal subjetividad, mas existe como procedente de ella."

Es posible que la mayor proximidad física y afectiva a los dos últimos haya hecho que yo, en épocas no muy pasadas, me apuntara a sus tesis, pero también lo hacían Rodrigo Bercovitz y Luis Díez-Picazo -discípulos de don Federico- y otros autores como Puig Ferriol o Gullón, representando, todos ellos, a la mayoría de la doctrina española, allá por 1985.

Poco después, con todo, ve la luz la Ley de Propiedad Intelectual de 1987, ley que hace un amplio tratamiento de las facultades o derechos morales del autor -inédito, divulgación, paternidad, integridad, modificación, arrepentimiento y acceso, en fin, al ejemplar único o raro de la

${ }^{27}$ Beltrán de Heredia, Construcción jurídica de los derechos de la personalidad, Madrid, 1976, p. 55.

${ }^{28}$ Lacruz Berdejo, "Prólogo" a la Propiedad intelectual. Su significado en la sociedad de la información, de Bondía Román, Madrid, 1988, p. 15. 
obra-, entendiendo que tales derechos son irrenunciables e inalienables (artículo 14) y admitiendo que algunos de ellos sean ejercidos por terceros, con posterioridad al fallecimiento del autor (artículos 15 y 16).

Tales connotaciones expresas me han llevado a pensar de nuevo sobre el asunto y ello hasta el punto de cambiar mi postura inicial, llegando al convencimiento de que, a la postre y si bien se mira, los más importantes derechos morales del autor no son otra cosa, en el fondo, que especificaciones, concreciones de clásicos derechos de la personalidad cuyo campo de acción se proyecta sobre las creaciones intelectuales, ampliándose, de algún modo, por ello -el inédito, por ejemplo, sería concreción de la intimidad, como la paternidad lo sería de la fama y el arrepentimiento del honor.

Este convencimiento -curiosamente- viene refrendado por lo dicho en textos doctrinales y normativos muy anteriores a 1987 y a 1985 incluso, textos que, aun conocidos, no habian sido tenidos suficientemente en cuenta por mí y con cuya cita termino.

El texto normativo es - nada más y nada menos- el artículo 6 bis del Convenio de Berna para la protección de las obras literarias y artísticas que, en su número 1, reza así:

"Independientemente de los derechos patrimoniales del autor e incluso después de la cesión de estos derechos, el autor conservará el derecho de reivindicar la paternidad de la obra y de oponerse a cualquier deformación, mutilación u otra modificación de la misma o a cualquier atentado a la misma que cause perjuicio a su honor o a su reputación" (a su honor o a su fama, podría muy bien decirse también).

El texto, que traduzco del francés y no tiene desperdicio, es de un maestro alemán, Ulmer, que dice del siguiente modo..$^{29}$

"El mérito principal de la Conferencia de Roma, de 1928, que modifica el Convenio de Berna, reside en el reconocimiento del derecho moral en el artículo 6 bis del mismo... Introducida por una proposición italiana, esta innovación es debida, principalmente, a Piola Caselli -un civilista, como no podía ser menos-. Las actas de la Conferencia dan cuenta del entusiasmo con que la mayoría de las delegaciones acogieron la proposición. La delegación alemana, por su parte, no tuvo dificultad alguna en aprobarla, dado que la protección de los intereses derivados del derecho de la personalidad estaba ya reconocida por la jurisprudencia y por la doctrina alemanas... La doctrina alemana, en efecto, se encontraba situada bajo

${ }^{29}$ Ulmer, “La République Fédérale d'Allemagne et l'Union de Berne”, en Le Droit d'auteur, marzo, 1986, p. 73ss.; la cita corresponde a la p. 76. 
la influencia de las tesis defendidas, sobre todo, por Gierke - de nuevo, Gierke-, según las cuales el derecho de autor era, por naturaleza, un derecho de la personalidad."

Con esta referencia a los derechos morales del autor, incardinables en los derechos de la personalidad, termino mi referencia a estos últimos. Es posible que, en lo dicho, falte algún árbol por dibujar, pero el bosque - grande y frondoso- representado por tales derechos creo que queda esbozado y asentado firmemente en terrenos -deslindados y amojonados- propios del derecho civil.

Volver al Ínice >> 